Article

\title{
The Thermal Transformation Arrest Phenomenon in NiCoMnAl Heusler Alloys
}

\author{
Xiao Xu ${ }^{1}$, Wataru Ito ${ }^{2}$, Masashi Tokunaga ${ }^{3}$, Takumi Kihara ${ }^{3}$, Kengo Oka $^{3}$, Rie Y. Umetsu ${ }^{4}$, \\ Takeshi Kanomata ${ }^{1,5}$ and Ryosuke Kainuma ${ }^{1, *}$ \\ ${ }^{1}$ Department of Materials Science, Graduate School of Engineering, Tohoku University, \\ Sendai 980-8579, Japan; E-Mails: xu@ material.tohoku.ac.jp (X.X.); \\ kanomata@tjcc.tohoku-gakuin.ac.jp (T.K.) \\ ${ }^{2}$ Materials Science and Engineering, Sendai National College of Technology, Natori 981-1239, Japan; \\ E-Mail: ito@sendai-nct.ac.jp \\ ${ }^{3}$ International MegaGauss Science Laboratory, Institute for Solid State Physics, The University of \\ Tokyo, Kashiwa 277-8581, Japan; E-Mails: tokunaga @issp.u-tokyo.ac.jp (M.T.); \\ kiharatakumi@issp.u-tokyo.ac.jp (T.K.); koka@msl.titech.ac.jp (K.O.) \\ ${ }^{4}$ Institute for Materials Research, Tohoku University, Sendai 980-8577, Japan; \\ E-Mail: rieume@imr.tohoku.ac.jp \\ ${ }^{5}$ Research Institute for Engineering and Technology, Tohoku Gakuin University, \\ Tagajo 985-8537, Japan \\ * Author to whom correspondence should be addressed; E-Mail: kainuma@ material.tohoku.ac.jp; \\ Tel.: +81-22-795-7321; Fax: +81-22-795-7323.
}

Received: 20 May 2013; in revised form: 26 June 2013 / Accepted: 14 August 2013 /

Published: 22 August 2013

\begin{abstract}
In this report, we present findings of systematic research on NiCoMnAl alloys, with the purpose of acquiring a higher thermal transformation arrest temperature $\left(T_{\mathrm{A}}\right)$. By systematic research, $T_{\mathrm{A}}$ in the $\mathrm{NiCoMnAl}$ alloy systems was raised up to $190 \mathrm{~K}$, compared to the highest $T_{\mathrm{A}}$ of $130 \mathrm{~K}$ in NiCoMnIn. For a selected alloy of $\mathrm{Ni}_{40} \mathrm{Co}_{10} \mathrm{Mn}_{33} \mathrm{Al}_{17}$, magnetization measurements were performed under a pulsed high magnetic field, and the critical magnetic field-temperature phase diagram was determined. The magnetic phase diagram for $\mathrm{Ni}_{50-x} \mathrm{Co}_{x} \mathrm{Mn}_{50-y} \mathrm{Al}_{y}$ was also established. Moreover, from the discussion that the formerly called "kinetic arrest phenomenon" has both thermodynamic and kinetic factors, we suggest a terminology change to the "thermal transformation arrest phenomenon".
\end{abstract}


Keywords: thermal transformation arrest; kinetic arrest; actuator materials; metamagnetic shape memory alloy; martensitic transformation; pulsed high magnetic field; NiCoMnIn; NiCoMnAl

\section{Introduction}

\subsection{Kinetic Arrest Phenomenon and Thermal Transformation Arrest Phenomenon}

It has been reported in $\mathrm{Ni}(\mathrm{Co}) \mathrm{MnIn}$ alloys that the martensitic transformation is interrupted during the cooling process, and the coexisting martensite and parent phases stay "stable" at low temperatures, even when the magnetic field is removed [1,2]. Moreover, as reported by Ito et al., when zero field heating was performed soon after field cooling, the "frozen" parent phase was "unfrozen", and a heating-induced martensitic transformation could be observed [2]. Based on the above experimental findings, it has been thought that the "frozen" state is caused by kinetic factors that prohibit the transformation from the parent phase to the martensite phase at extremely low temperatures. Hence, this phenomenon has been termed the kinetic arrest (KA) phenomenon, and the corresponding temperature, at which the martensitic transformation is arrested, has been called the KA temperature.

Subsequently, the KA phenomenon was found in other NiMn-based alloy systems, such as $\mathrm{Ni}_{33} \mathrm{Co}_{13.4} \mathrm{Mn}_{39.7} \mathrm{Ga}_{13.9}$ [3], $\mathrm{Ni}_{45} \mathrm{Co}_{5} \mathrm{Mn}_{31} \mathrm{Al}_{19}$ [4] and $\mathrm{Ni}_{37} \mathrm{Co}_{11} \mathrm{Mn}_{42.5} \mathrm{Sn}_{9.5}$ [5]. For these Metamagnetic Shape Memory Alloys (MMSMAs), the ferromagnetic parent phase can be induced by applying a magnetic field from the martensite phase, as first reported in NiCoMnIn [6]. Thus, by magnetization measurements at various temperatures below the reverse martensitic transformation starting temperature $\left(T_{\mathrm{A}_{\mathrm{s}}}\right)$, the magnetic fields of critical transition, i.e., the reverse martensitic transformation finishing magnetic field $\left(H_{\mathrm{A}_{\mathrm{f}}}\right)$ and the forward martensitic transformation starting magnetic field $\left(H_{\mathrm{M}_{\mathrm{s}}}\right)$, can be determined. By summarizing the results of $\mathrm{Ni}_{45} \mathrm{Co}_{5} \mathrm{Mn}_{36.7} \mathrm{In}_{13.3}$ [2], $\mathrm{Ni}_{33} \mathrm{Co}_{13.4} \mathrm{Mn}_{39.7} \mathrm{Ga}_{13.9}$ [3], $\mathrm{Ni}_{45} \mathrm{Co}_{5} \mathrm{Mn}_{31} \mathrm{Al}_{19}$ [4] and $\mathrm{Ni}_{37} \mathrm{Co}_{11} \mathrm{Mn}_{42.5} \mathrm{Sn}_{9.5}$ [5], it can be concluded that the magnetic field hysteresis, which is defined by $H_{\text {hys }}=H_{\mathrm{A}_{\mathrm{f}}}-H_{\mathrm{M}_{\mathrm{s}}}$, greatly increases at low temperatures, which strongly supports the kinetic nature of the KA phenomenon. Moreover, besides the enlargement of the $H_{\text {hys }}$ at low temperatures, other experimental facts also support the kinetic nature of this unique phenomenon. For NiCoMnIn alloys, Ito et al. observed the isothermal behavior of martensitic transformation [7], and Lee et al. investigated the Time-Temperature-Transformation (TTT) diagram [8], where the time-dependent nucleation of the martensite phase has been confirmed. On the other hand, Sharma et al. [1] and Kustov et al. [9] systematically investigated the relaxation behavior during martensitic transformation, where the time-dependent growth of the martensite phase has also been confirmed. Furthermore, Nayak et al. found that the transformation hysteresis changes with the sweeping speed of the temperature and the magnetic field in the NiCoMnSb system [10]. Our group has also confirmed that for NiCoMnIn, the $H_{\text {hys }}$ is greatly enlarged under a pulsed magnetic field, as compared to that under a static magnetic field [11]. Recently, in situ observation by our group has also confirmed that if the 
thermal activation energy related to the kinetic behavior differs, the optical microstructure also shows distinctive features [12].

Nevertheless, the derivation by Ito et al. [2] has shown that the KA phenomenon also has a thermodynamic nature. Generally, for the case of magnetic field-induced reverse martensitic transformation, the magnetic field hysteresis loop reflects the dissipation energy during the forward and reverse martensitic transformation. Therefore, the thermodynamic equilibrium condition between the two phases exists between $H_{\mathrm{M}_{\mathrm{s}}}$ and $H_{\mathrm{A}_{\mathrm{f}}}$, and this condition is neither related to nor affected by kinetic factors. Physically, if the magnetization differences between the two phases $(\Delta M)$ at $H_{\mathrm{M}_{\mathrm{s}}}$ and $H_{\mathrm{A}_{\mathrm{f}}}$ are almost equal, $H_{0}=\left(H_{\mathrm{A}_{\mathrm{f}}}+H_{\mathrm{M}_{\mathrm{s}}}\right) / 2$ can be assumed as the equilibrium magnetic field at which the parent phase and the martensite phase have an equal Gibbs free energy under the condition that a small amount of the martensite phase exists in the parent austenite matrix [13]. It can be concluded from [2-5] that $H_{0}$ increases with decreasing temperature and becomes almost constant below certain temperatures (KA temperatures), which is a common feature of all four alloys. The Clausius-Clapeyron equation between the magnetic field and temperature gives:

$$
\frac{\mathrm{d} H_{0}}{\mathrm{~d} T}=-\frac{\Delta S}{\Delta M}
$$

where $\Delta M$ and $\Delta S$ are the magnetization difference and the entropy change during the transformation, respectively. Since $\Delta M$ does not change so much in a relatively small range of temperature far below the Curie temperature, $\Delta S$ should be approximately proportional to $\mathrm{d} H_{0} / \mathrm{d} T$ for the absolute value. Thus, one can conclude that, generally, $\Delta S$ becomes zero at the KA temperature. Since the driving force, $\Delta G$, for the thermal transformation can be estimated by $\Delta G \approx \Delta S \cdot \Delta T$, where $\Delta T$ stands for supercooling, the transformation will stop when $\Delta S$ becomes zero. This is considered to be the thermodynamic cause of the KA phenomenon. This has also been well agreed by Cesari et al. [14]. They have suggested the term of "thermodynamic arrest" in order to reflect the thermodynamic nature of this phenomenon.

In other words, the arrested parent phase during field cooling can be considered to be a thermodynamic phenomenon, while when the magnetic field is removed, it does not transform to the martensite phase, mainly because of kinetic reasons. Therefore, the former name, "kinetic arrest phenomenon", may mislead as to the nature of this phenomenon. In this article, we suggest and will from now on neutrally call this phenomenon the "thermal transformation arrest (TTA) phenomenon" and the corresponding temperature, at which the forward martensitic transformation stops, to be the "thermal transformation arrest temperature $\left(T_{\mathrm{A}}\right)$ "'.

\subsection{Considerations of the Thermal Transformation Arrest Phenomenon for Practical Applications}

The TTA phenomenon is not only an interesting physical phenomenon, but it also has important implications for practical applications.

This is shown schematically in Figure 1. In the upper part of Figure 1(a), the results of the thermomagnetization (MT) measurement for a heating process of an MMSMA is shown. Under zero field heating (ZFH), where the applied magnetic field is very small, the martensite phase with weak magnetism changes to the parent phase with ferromagnetism at $T_{\mathrm{A}_{\mathrm{f}}}$. While under field heating (FH), where a strong magnetic field is applied, the transformation temperature decreases to $T_{\mathrm{A}_{\mathrm{f}}}^{\prime}$, the MT curve 
being shown by the purple line. Moreover, when considering practical use, the maximum magnetic field a permanent magnet can produce is around $1.5 \mathrm{~T}$, and thus, the temperature change is small, as indicated by the purple arrow. Since the process of magnetic field-induced reverse martensitic transformation is used for actuators, the consideration only focuses on the heating process, and the temperature range available for practical application is very limited, as shown by $\Delta T_{0 \mathrm{p}}$. The correspondence of the MT with the critical magnetic field-temperature $\left(H_{0}-T\right)$ diagram is shown in the lower part of Figure 1(a), where the definitions of $H_{\mathrm{A}_{\mathrm{f}}}$ and $H_{\mathrm{M}_{\mathrm{s}}}$ in the $H_{0}-T$ diagram are schematically shown in the inset. It can be seen that the linear part of the diagram is used and that the bending part corresponding to the TTA phenomenon is not related to this condition. Before proceeding to an explanation of the next figure, it should be pointed out that all the figures shown in Figure 1 are schematic, and this is only the case for an ideal MMSMA. For an actual MMSMA, such as NiCoMnIn, around 3-5 T of magnetic field is required for a reversible MFIT [6]. Therefore, $1.5 \mathrm{~T}$ is far from enough. For other systems, the required magnetic field is even larger.

Figure 1. These figures illustrate how the thermal transformation arrest phenomenon can be used to improve metamagnetic shape memory alloys for their application as actuators. (a) An illustration of an alloy with only a limited temperature range available for application, where the thermal transformation arrest phenomenon is not employed. (b) By adjusting the composition of the alloy, the flat portion of the thermal transformation arrest phenomenon is utilized to obtain a wider temperature window for application. This process has been shown to be easy to realize by former studies. (c) It is illustrated that further improvement of the temperature range is realized by a smaller magnetic-field hysteresis and a higher thermal transformation arrest temperature. In (a) to (c), $\Delta T_{0 \mathrm{p}}$ means the temperature range available for practical applications. Moreover, the illustrations here are under ideal conditions with the employment of the thermal transformation arrest phenomenon. Refer to the text for details.

(a)

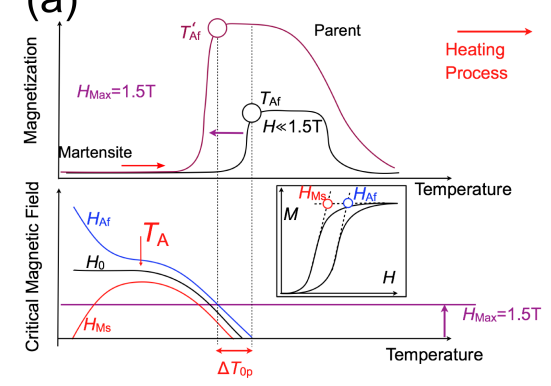

(b)

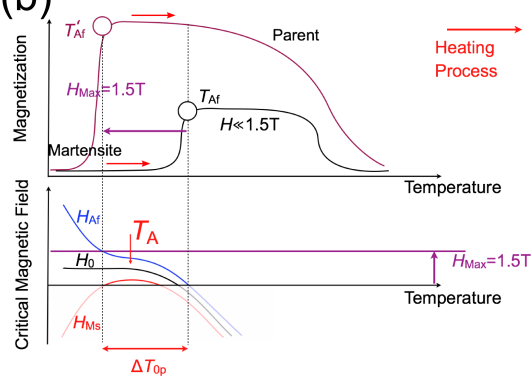

(c)

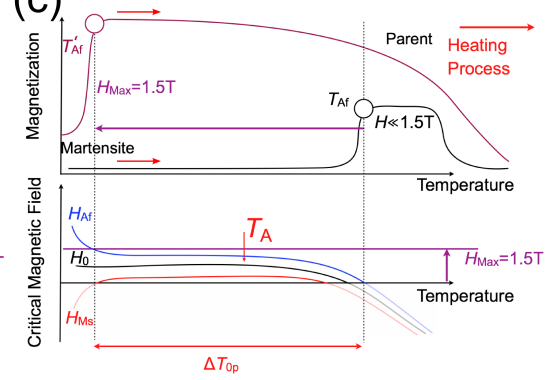

For practical use, a temperature window wider than the narrow one shown in Figure 1(a) is required. As reported earlier, by simple variation of the composition, the horn-shaped $H_{0}-T$ diagram can be easily shifted vertically [15]. Figure 1(b) shows the condition where the diagram is shifted downwards. As the MT curves above show, by applying a magnetic field, $T_{\mathrm{A}_{\mathrm{f}}}$ decreases more than the condition in Figure 1(a). Therefore, by using the flat portion of the diagram where the TTA phenomenon appears, a wider temperature window becomes available for applications, as shown by $\Delta T_{0 \mathrm{p}}$.

However, to get an even wider temperature window, attempts must be made to modify the shape of the horn-shaped $H_{0}-T$ diagram. As shown in Figure 1(c), if an alloy with a much higher $T_{\mathrm{A}}$ is obtained, 
a larger temperature range of the flat portion in the $H_{0}-T$ diagram will be obtained, and thus, the upper limit of the temperature window can be greatly raised. Moreover, if the enlargement of $H_{\text {hys }}$ at low temperatures can be suppressed, the lower limit of the temperature window can be further extended, as shown in the lower part of Figure 1(c). However, approaches for modification of the shape of the $H_{0}-T$ diagram have not been reported to date.

\subsection{The Purpose of This Study}

In this report, we focus on efforts to raise the $T_{\mathrm{A}}$ in NiMn-based alloy systems. In NiCoMnIn, the tendency can be concluded from previous reports. It has been found that for $\mathrm{Ni}_{50-x} \mathrm{Co}_{x} \mathrm{Mn}_{50-y} \operatorname{In}_{y}$, the $T_{\mathrm{A}}$ increases from $73 \mathrm{~K}$ [16] to $105 \mathrm{~K}$ [17] with 2.5 at\% dopant of Co and to $129 \mathrm{~K}$ [2] with 5 at\% dopant of Co. Thus, if more Co can be added to NiMnIn, alloys with higher $T_{\mathrm{A}}$ can be expected. However, as reported by Ito et al., with a 7.5 at\% addition of Co, the parent phase decomposes into two phases [18]. Therefore, we have to search for alloy systems that have larger Co solubility. As shown by Kainuma et al., though both the parent phase and martensite phase of NiMnAl alloy have very weak magnetism, by the substitution of $\mathrm{Co}$ for $\mathrm{Ni}$, the magnetism of the parent phase drastically becomes ferromagnetic, while the martensite phase remains as weak magnetism [19]. Therefore, the magnetic relationship in NiCoMnAl between the parent and martensite phases is similar to that of the NiCoMnIn alloy system, and metamagnetic transformation has also been confirmed in NiCoMnAl [19]. In the original report [19], 10 at\% of Co was added, and even larger solubility of Co, and, thus, a higher $T_{\mathrm{A}}$, can be expected. In the present research, a systematical investigation on the NiCoMnAl alloy system was carried out, with the purpose of searching for a higher $T_{\mathrm{A}}$.

\section{Experimental Procedures}

$\mathrm{Ni}_{50-x} \mathrm{Co}_{x} \mathrm{Mn}_{50-y} \mathrm{Al}_{y}\left(x=5,10,15, y=12-19, \mathrm{Co}_{x} \mathrm{Al}_{y}\right.$ for short) samples were prepared by induction melting in an argon atmosphere. Heat treatment was conducted at 1,373 $\mathrm{K}$ for $24 \mathrm{~h}$, followed by water quenching. Composition analysis was carried out by an Electron Probe Microanalyzer (EPMA), and the results are summarized in Table 1. MT measurements were performed by a Vibration Sample Magnetometer and a SQUIDmagnetometer at a sweeping speed of $2 \mathrm{~K} / \mathrm{min}$. Magnetization measurements under a pulsed magnetic field up to $55 \mathrm{~T}$ were measured by induction using coaxial pickup coils [20] at the Institute for Solid State Physics, the University of Tokyo.

Table 1. Compositions of $\mathrm{Ni}_{50-x} \mathrm{Co}_{x} \mathrm{Mn}_{50-y} \mathrm{Al}_{y}\left(\mathrm{Co}_{x} \mathrm{Al}_{y}\right.$ for short) alloys were analyzed by Electron Probe Microanalyzer (EPMA). The composition data listed here are in atomic percentage. Data of the Curie temperature $\left(T_{\mathrm{C}}\right)$ and martensitic transformation starting temperature $\left(T_{\mathrm{M}_{\mathrm{s}}}\right)$ are also listed.

\begin{tabular}{|c|c|c|c|c|c|c|}
\hline Nominal & Ni at\% & Co at\% & Mn at & Al at \% & $T_{\mathrm{C}}$ & $T_{\mathrm{M}_{\mathrm{s}}}$ \\
\hline $\mathrm{Co}_{5} \mathrm{Al}_{18.5}$ & 44.7 & 5.1 & 32.0 & 18.2 & - & 322 \\
\hline $\mathrm{Co}_{5} \mathrm{Al}_{20}$ & 44.4 & 5.1 & 30.5 & 20.0 & 269 & 129 \\
\hline
\end{tabular}


Table 1. Cont.

\begin{tabular}{|c|c|c|c|c|c|c|}
\hline Nominal & Ni at\% & Co at\% & Mn a & oAl at $\%$ & $T_{\mathrm{C}}$ & $T_{\mathrm{M}_{\mathrm{s}}}$ \\
\hline $\mathrm{Co}_{5} \mathrm{Al}_{21}$ & 44.4 & 5.1 & 29.4 & 21.1 & 257 & - \\
\hline $\mathrm{Co}_{10} \mathrm{Al}_{17}$ & 39.7 & 10.2 & 33.7 & 16.4 & 428 & 351 \\
\hline $\mathrm{Co}_{10} \mathrm{Al}_{17.5}$ & 39.9 & 10.1 & 33.3 & 16.7 & 423 & 252 \\
\hline $\mathrm{Co}_{10} \mathrm{Al}_{19}$ & 39.9 & 10.1 & 30.6 & 19.4 & 394 & - \\
\hline $\mathrm{Co}_{15} \mathrm{Al}_{12}$ & 34.7 & 14.8 & 38.8 & 11.7 & - & 525 \\
\hline $\mathrm{Co}_{15} \mathrm{Al}_{14}$ & 34.5 & 14.8 & 37.0 & 13.7 & 527 & 450 \\
\hline $\mathrm{Co}_{15} \mathrm{Al}_{14.5}$ & 35.0 & 15.2 & 35.6 & 14.2 & 516 & 390 \\
\hline $\mathrm{Co}_{15} \mathrm{Al}_{14.8}$ & 35.0 & 15.0 & 35.6 & 14.4 & & 360 \\
\hline $\mathrm{Co}_{15} \mathrm{Al}_{15}$ & 34.5 & 15.0 & 35.8 & 14.7 & 514 & 332 \\
\hline $\mathrm{Co}_{15} \mathrm{Al}_{15.5}$ & 34.5 & 15.1 & 35.4 & 15.0 & 510 & - \\
\hline $\mathrm{Co}_{15} \mathrm{Al}_{17}$ & 34.9 & 15.3 & 32.8 & 17.0 & 503 & - \\
\hline
\end{tabular}

\section{Results and Discussion}

\subsection{Thermal Transformation Arrest Temperatures in Co-Doped Alloys}

In the $\mathrm{Co}_{x} \mathrm{Al}_{y}$ system, the TTA phenomenon was first realized with the compositions of $\mathrm{Co}_{5} \mathrm{Al}_{y}$ [4]. As shown in Figure 2(a), the martensitic transformation is interrupted at around $40 \mathrm{~K}$. The application of a magnetic field has a drastic effect on the behavior of martensitic transformation. For this alloy, with the application of a higher magnetic field, the magnetization at low temperatures continues growing, and the martensitic transformation almost stopped under a $7 \mathrm{~T}$ field cooling, suggesting a strong arresting.

By the arrangement of composition, the TTA phenomenon was also realized in $\mathrm{Co}_{10} \mathrm{Al}_{x}$ in this study. Figure 2(b) shows the MT curves of $\mathrm{Co}_{10} \mathrm{Al}_{17.5}$ under magnetic fields of $0.05,1,3$ and $5 \mathrm{~T}$. Martensitic transformation starting temperature $\left(T_{\mathrm{M}_{\mathrm{s}}}\right)$ was observed to decrease with increasing applied magnetic field. As explained in Figure 2(a), with the increase of the applied magnetic field, the magnetization in the low temperatures part also increases. This also indicates the appearance of the TTA phenomenon, and the $T_{\mathrm{A}}$ is determined to be around $160 \mathrm{~K}$.

Moreover, Figure 2(c) shows the magnetization curves of $\mathrm{Co}_{15} \mathrm{Al}_{15}$ under magnetic fields of 3, 5 and $7 \mathrm{~T}$, which follows Khovaylo et al. [21]. Due to the fact that both the $T_{\mathrm{C}}$ and the $T_{\mathrm{A}_{\mathrm{f}}}$ are high for this sample, the temperature hysteresis could not be fully measured. For this alloy, the martensitic transformation is also interrupted, and the $T_{\mathrm{A}}$ is determined to be $190 \mathrm{~K}$. Thus, as shown in Figure 2, the doping of Co into NiMnAl is also found to be effective to raise the $T_{\mathrm{A}}$, and a high $T_{\mathrm{A}}$ of about $190 \mathrm{~K}$ was obtained in the $\mathrm{Co}_{15} \mathrm{Al}_{x}$. 
Figure 2. Thermomagnetization curves under different magnetic fields for (a) $\mathrm{Ni}_{45} \mathrm{Co}_{5} \mathrm{Mn}_{30} \mathrm{Al}_{20}\left(\mathrm{Co}_{5} \mathrm{Al}_{20}\right)$ [4], (b) $\mathrm{Ni}_{40} \mathrm{Co}_{10} \mathrm{Mn}_{32.5} \mathrm{Al}_{17.5}\left(\mathrm{Co}_{10} \mathrm{Al}_{17.5}\right)$ and (c) $\mathrm{Ni}_{35} \mathrm{Co}_{15} \mathrm{Mn}_{35} \mathrm{Al}_{15}\left(\mathrm{Co}_{15} \mathrm{Al}_{15}\right)$ [21]. It can be seen that, for all of the three compositions, by applying stronger magnetic fields, the magnetization at low temperatures continues increasing. This suggests that the thermal transformation arrest phenomenon occurs for all three alloys. The corresponding thermal transformation arrest temperatures are indicated by $T_{\mathrm{A}}$ in the figures.
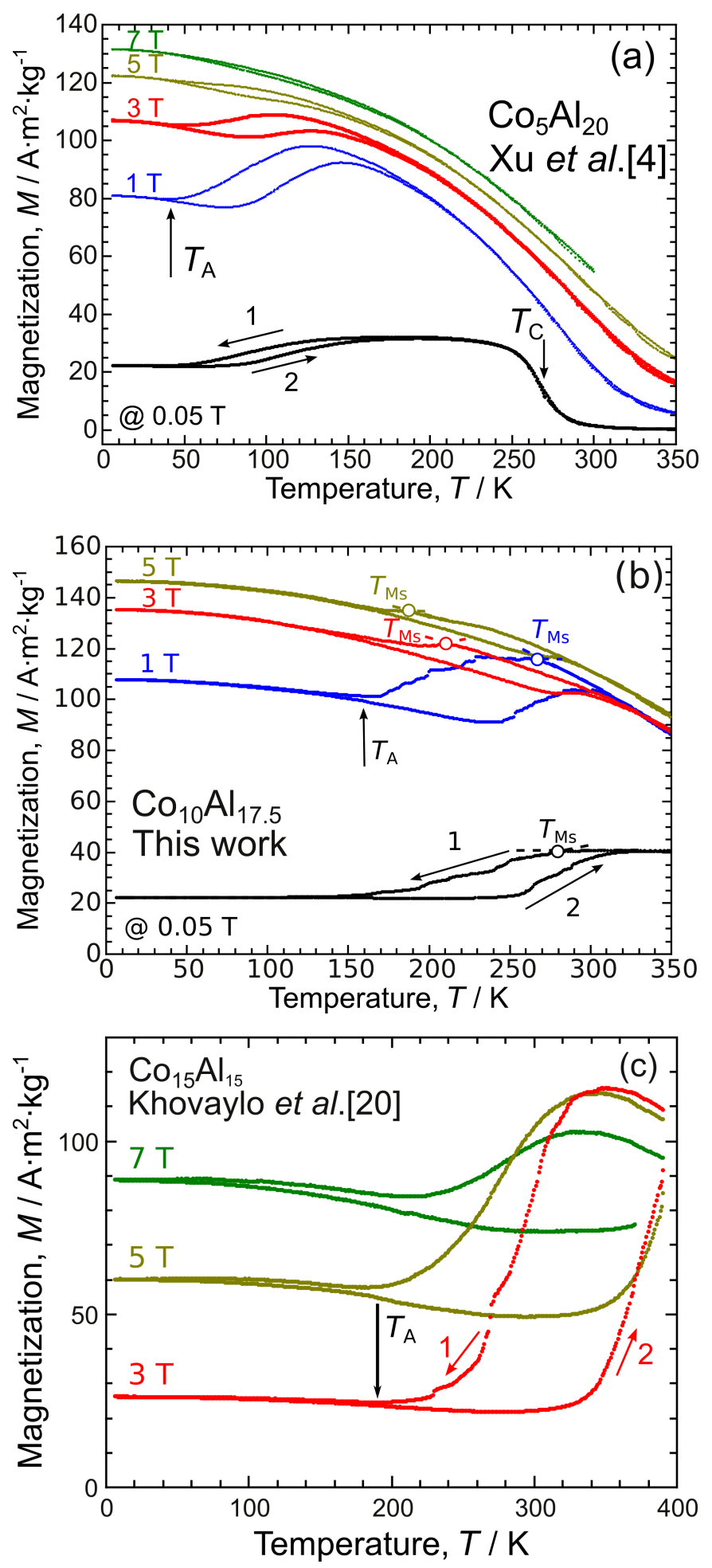


\subsection{Magnetization Measurements in Pulsed Magnetic Field}

As first reported for NiCoMnIn, the $H_{0}-T$ phase diagram for the alloys with TTA behavior show horn-shaped curves [2]. The $H_{\mathrm{M}_{\mathrm{s}}}$ and $H_{\mathrm{A}_{\mathrm{f}}}$ make up the lower and upper branches, respectively, and the $H_{0}$ becomes constant below the $T_{\mathrm{A}}$. This behavior has been confirmed for the first time in $\mathrm{Co}_{5} \mathrm{Al}_{19}$ [4] in the the $\mathrm{NiCoMnAl}$ alloy system, and for $\mathrm{Co}_{10} \mathrm{Al}_{17}$, the investigation was conducted in this study by magnetization measurements under a pulsed magnetic field.

Figure 3. (a) Magnetization curves at different temperatures under a pulsed magnetic field for $\mathrm{Ni}_{40} \mathrm{Co}_{10} \mathrm{Mn}_{33} \mathrm{Al}_{17}$ at 50,100, 200 and $300 \mathrm{~K}$. (b) The corresponding transformation magnetic fields, i.e., the forward martensitic transformation starting magnetic field, $H_{\mathrm{M}_{\mathrm{s}}}$, and the reverse martensitic transformation finishing magnetic field, $H_{\mathrm{A}_{\mathrm{f}}}$, are indicated in the figure. For reference, the results for $\mathrm{Ni}_{45} \mathrm{Co}_{5} \mathrm{Mn}_{31} \mathrm{Al}_{19}$ [4] are also shown. (c) The magnetic field hysteresis, $H_{\text {hys }} / 2=\left(H_{\mathrm{A}_{\mathrm{f}}}-H_{\mathrm{M}_{\mathrm{s}}}\right) / 2$, for $\mathrm{Ni}_{40} \mathrm{Co}_{10} \mathrm{Mn}_{33} \mathrm{Al}_{17}$ and $\mathrm{Ni}_{45} \mathrm{Co}_{5} \mathrm{Mn}_{31} \mathrm{Al}_{19}$ [4,12] are summarized. For $50 \mathrm{~K}$, as shown in (a), the difference of the magnetizing and demagnetizing branches is taken to be $H_{\text {hys }}$ and shown by an open circle. $H_{\mathrm{TA}}$ and $H_{\mu}$ suggest the thermally activated and athermal terms of $H_{\text {hys }} / 2$, respectively.
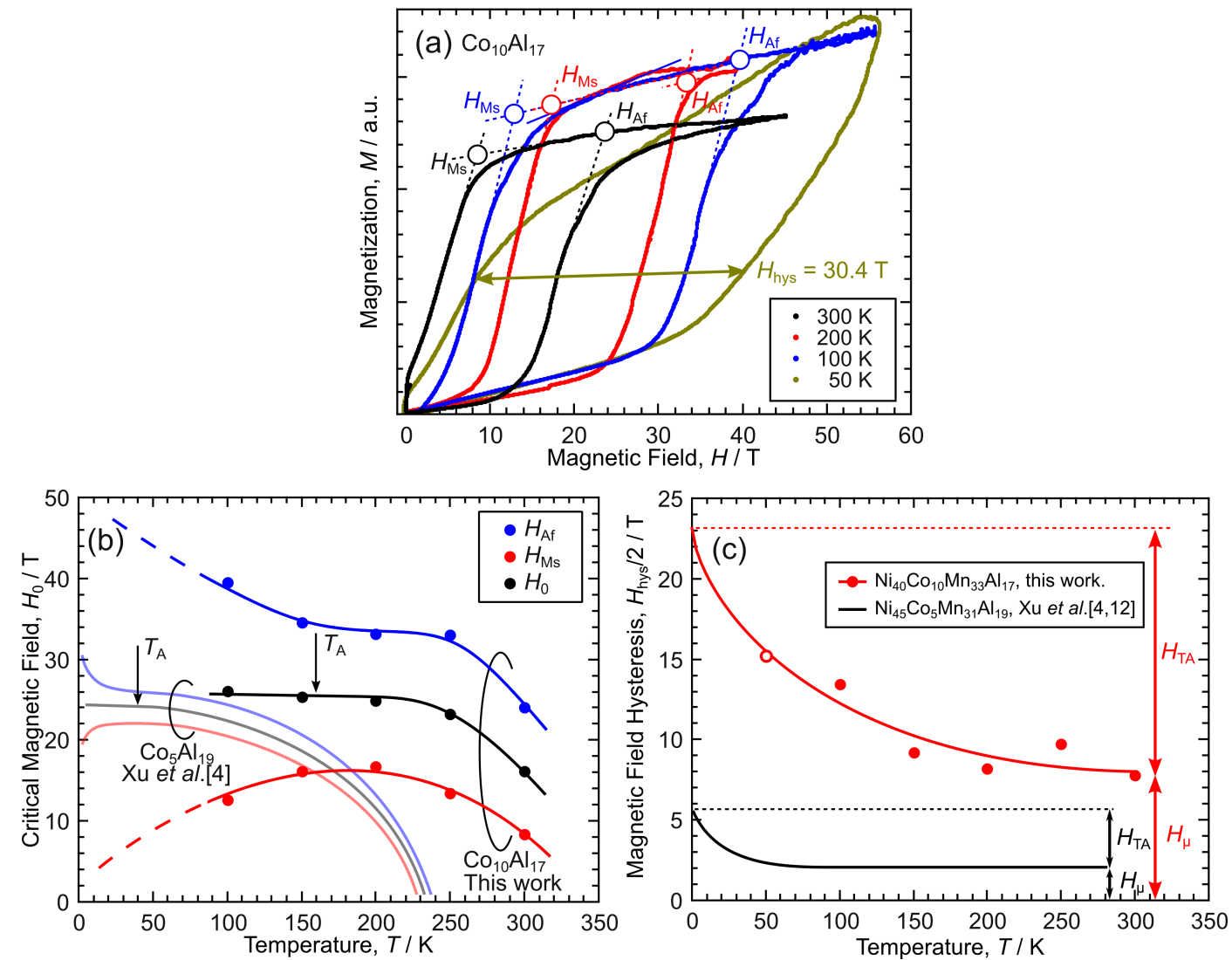

Figure 3(a) shows the magnetization curves for $\mathrm{Co}_{10} \mathrm{Al}_{17}$ up to $55 \mathrm{~T}$ at 50, 100, 200 and $300 \mathrm{~K}$. Raw data of the differentiations of magnetization and magnetic field against measurement time are obtained, and the integrals yield the magnetization-magnetic field curves. Normally, calibration for obtaining the integral constants is conducted using the results of the magnetization measurements obtained by SQUID in the low magnetic field region, and the absolute values of magnetization can be also obtained. 
Especially for the case when a ferromagnetic-like behavior can be observed in low magnetic fields, the calibration becomes very easy. However, the calibration for the integral constants was not successful for this sample, since the magnetism in the martensite phase (which is the only state we can obtain in low magnetic fields) is paramagnetic-like. Therefore, the unit in Figure 3(a) is shown as a.u.. Nevertheless, we can clearly observe that magnetic field-induced reverse martensitic transformation for all the temperatures and an almost full parent phase were obtained, except for $50 \mathrm{~K}$. Moreover, the determination of critical magnetic fields $\left(H_{\mathrm{M}_{\mathrm{s}}}\right.$ and $\left.H_{\mathrm{A}_{\mathrm{f}}}\right)$ by extrapolation, as shown in Figure 3(a), is also not affected at all by the arbitrary values of magnetization. For $50 \mathrm{~K}$, since the reverse martensitic transformation is not complete, $H_{\mathrm{M}_{\mathrm{s}}}$ and $H_{\mathrm{A}_{\mathrm{f}}}$ could not be determined. Therefore, it can be generally concluded that the critical magnetic fields shift higher as the measurement temperature becomes lower.

The critical magnetic fields are summarized in Figure 3(b), and the results for $\mathrm{Co}_{5} \mathrm{Al}_{19}$ [4] are plotted. For $\mathrm{Co}_{10} \mathrm{Al}_{17}$, it can be seen that, below the $T_{\mathrm{A}}, H_{0}$ becomes almost constant, while the $H_{\text {hys }}$ begins to enlarge below this temperature. However, if the results of $\mathrm{Co}_{10} \mathrm{Al}_{17}$ and $\mathrm{Co}_{5} \mathrm{Al}_{19}$ are compared, one can easily find two differences between them. First, the $T_{\mathrm{A}}$ is much higher for $\mathrm{Co}_{10} \mathrm{Al}_{17}$, as already stated in Figure 2. Second, the $H_{\text {hys }} / 2$ around $T_{\mathrm{A}}$ is only about 2-3 $\mathrm{T}$ for $\mathrm{Co}_{5} \mathrm{Al}_{19}$, while that of $\mathrm{Co}_{10} \mathrm{Al}_{17}$ reaches $10 \mathrm{~T}$. It should be noted that both of the results of the referenced $\mathrm{Co}_{5} \mathrm{Al}_{19}$ or $\mathrm{Co}_{10} \mathrm{Al}_{17}$ by this study were investigated under a pulsed magnetic field. As stated in the introduction, the $H_{\text {hys }}$ is enlarged under a pulsed magnetic field for the measurement of NiCoMnIn, compared to that under a static magnetic field [11]; a smaller $H_{\text {hys }}$ would be expected for $\mathrm{Co}_{10} \mathrm{Al}_{17}$ if the magnetization measurement under a static magnetic field were possible. For investigations on $H_{\text {hys }}$, recent studies by our group have given some phenomenological understanding of its breakdown and temperature dependency [12,22]. Here, we plot the $H_{\text {hys }} / 2$ for both $\mathrm{Co}_{5} \mathrm{Al}_{19}$ and $\mathrm{Co}_{10} \mathrm{Al}_{17}$ in Figure 3(c), where the $H_{\text {hys }}$ for $50 \mathrm{~K}$ is estimated by the difference of the magnetizing and demagnetizing branches in Figure 3(a) and is shown by an open circle in Figure 3(c). As shown by the findings of Umetsu et al. [22], it is found that both the athermal term $\left(H_{\mu}\right)$ and the thermally activated term $\left(H_{\mathrm{TA}}\right)$ for $\mathrm{Co}_{10} \mathrm{Al}_{17}$ are much larger than those of $\mathrm{Co}_{5} \mathrm{Al}_{19}$. In Figure 3(c), the red solid line for fitting the $H_{\text {hys }} / 2$ of $\mathrm{Co}_{10} \mathrm{Al}_{17}$ is given by [22]:

$$
H_{\mathrm{hys}}(T) / 2=H_{\mu}+H_{\mathrm{TA}}=H_{\mu}+H_{\mathrm{TA}}(0)\left[1-\left(\frac{m k_{\mathrm{B}} T}{Q_{0 \mathrm{~K}}}\right)^{1 / q}\right]^{1 / p}
$$

with $q=3 / 2, p=1 / 2, H_{\mu}=8.0 \mathrm{~T}, H_{\mathrm{TA}}(0)=15.1 \mathrm{~T}$ and $m / Q_{0 \mathrm{~K}}=37.2 \mathrm{eV}^{-1}$, where $T$, being the temperature, $H_{\mathrm{TA}}(0)$, being the limit value of $H_{\mathrm{TA}}$ at $0 \mathrm{~K}, k_{\mathrm{B}}$, being the Boltzmann constant, $m$, being a dimensionless constant relating to the sweeping rate of the magnetic field, and $Q_{0 \mathrm{~K}}$, being the activation energy for overcoming the kinetic barrier without thermal assist. Therefore, according to this model, the $H_{\text {hys }}$ at temperatures near $0 \mathrm{~K}$ will be more than $46 \mathrm{~T}$, and the $H_{\mathrm{A}_{\mathrm{f}}}$ is expected to be around $49 \mathrm{~T}$. The expected tendencies of $H_{\mathrm{M}_{\mathrm{s}}}$ and $H_{\mathrm{A}_{\mathrm{f}}}$ are illustrated by dashed lines in Figure 3(b) (note that with the definition of $H_{\mathrm{A}_{\mathrm{f}}}$ by extrapolation, the magnetic field over which the magnetizing and demagnetizing curves overlap, i.e., the magnetic field at which reverse martensitic transformation actually finishes, is much higher than the $H_{\mathrm{A}_{\mathrm{f}}}$ shown in Figure 3(b)). However, the reason for the large differences in $H_{\text {hys }}$ between the two alloys is still not clear, and neither is the nature of the $H_{\text {hys }}$. Thus, further investigations are required in the future to understand the physical origins of the $H_{\text {hys }}$. 


\subsection{Determination of the Magnetic Phase Diagram for $\mathrm{Ni}_{50-x} \mathrm{Co}_{x} \mathrm{Mn}_{50-y} A l_{y}$}

Figure 4 shows the thermomagnetization curves for $\mathrm{Co}_{x} \mathrm{Al}_{y}$, where none of the samples show martensitic transformation behaviors. For stoichiometric samples $(y=25)$, no martensitic transformation can be observed [23], and the samples shown in Figure 4 are nearer stoichiometry than the samples showing martensitic transformations, as illustrated in Figure 2. Only Curie temperature $\left(T_{\mathrm{C}}\right)$ is observed, and it is defined to be the temperature at which the differentiation shows a minimum (not shown). It can be observed that the $T_{\mathrm{C}}$ is greatly raised by the addition of Co content, which is consistent with the former report on $\mathrm{Co}_{x} \mathrm{Al}_{25}$ samples [23], and has the same tendency as compared with NiCoMnIn [18,24] and NiCoMnGa [25,26].

Figure 4. Thermomagnetization curves for $\mathrm{Ni}_{50-x} \mathrm{Co}_{x} \mathrm{Mn}_{50-y} \mathrm{Al}_{y}\left(\mathrm{Co}_{x} \mathrm{Al}_{y}\right.$ for short) samples without martensitic transformation behavior under the magnetic field of $1 \mathrm{~T}$. Curie temperatures $\left(T_{\mathrm{C}}\right)$ are detected, and it can be observed that $T_{\mathrm{C}}$ increases with increasing Co content.

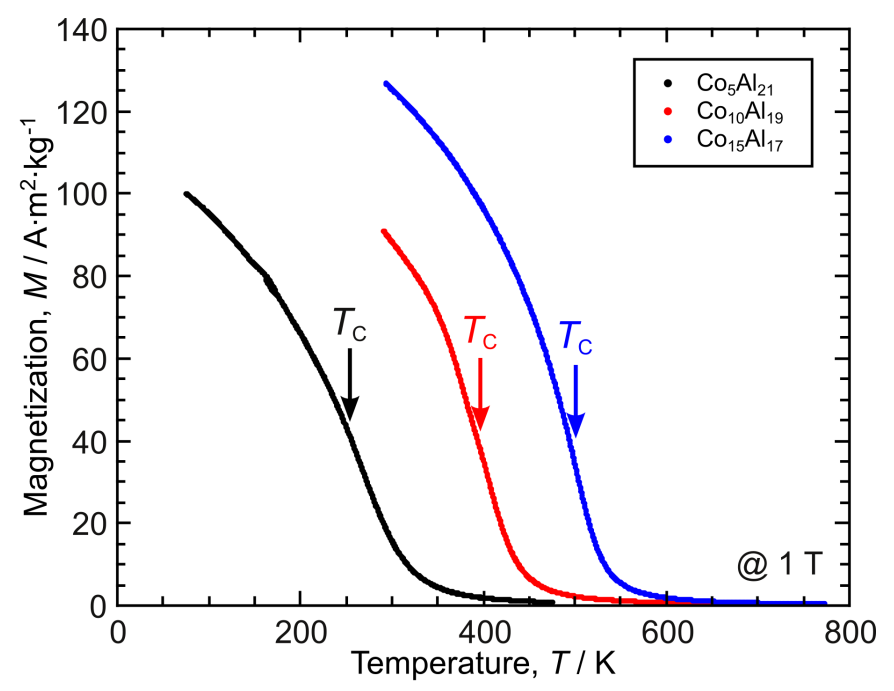

Similar measurements of other samples shown in Table 1 were also performed; the obtained $T_{\mathrm{M}_{\mathrm{s}}}$ and $T_{\mathrm{C}}$ are listed in Table 1 and summarized in Figure 5. It can be seen that for the series of samples with the same Co content, the $T_{\mathrm{M}_{\mathrm{s}}}$ decreases with increasing $\mathrm{Al}$ content, which is the same as NiMnAl [28]. However, the decreasing tendency enhances when below the $T_{\mathrm{C}}$, which is similar to the case of NiCoMnIn alloys [18]. The tendencies, as well as the values of the transition temperatures are consistent with former reports [23,27-29], as shown in Figure 5. It should be also pointed out that, for solution-treated NiMnAl ternary alloys, the parent phase with a $B 2$ structure is antiferromagnetic and the $T_{\mathrm{C}}$ does not exist [28]. With aging treatment at low temperatures, the crystal structure changes from $B 2$ to $L 2_{1}$, and this results in ferromagnetism in the parent phase near the stoichiometric composition $[28,30]$. Though not shown in this report, NiCoMnAl alloys in this study also showed the same tendency, i.e., the $T_{\mathrm{C}}$ increases after aging at low temperatures. The $T_{\mathrm{A}}$ s obtained in Figure 2 are also indicated in Figure 5. It was found that the $T_{\mathrm{A}}$ does not seem to change in the same series of samples with the same Co composition. Furthermore, the Co addition greatly raises $T_{\mathrm{A}}$. The TTA phenomenon has been schematically explained by Gibbs free energy curves [18] and is believed to be greatly affected 
by the ferromagnetic state of the parent phase. Therefore, the increase of $T_{\mathrm{A}}$ in NiCoMnAl can be easily understood, since the addition of Co strongly raises the $T_{\mathrm{C}}$ of the parent phase. Though $T_{\mathrm{A}}$ was successfully raised in NiCoMnAl alloys, which satisfies the purpose of this study, the $H_{\text {hys }}$ is greatly enlarged, and this is extremely unfavorable from the viewpoint of applications. To date, the way to decreasing the $H_{\text {hys }}$ is still unknown and remains to be investigated further in the future.

Figure 5. Magnetic phase diagram for $\mathrm{Ni}_{50-x} \mathrm{Co}_{x} \mathrm{Mn}_{50-y} \mathrm{Al}_{y}$ with $x=5,10$ and 15 . Martensitic transformation temperatures, $T_{\mathrm{M}_{\mathrm{s}}}$, Curie temperature, $T_{\mathrm{C}}$, and the thermal transformation arrest temperature, $T_{\mathrm{A}}$, are indicated. Transformation temperatures reported for NiMn [27], $\mathrm{Ni}_{50} \mathrm{Mn}_{50-y} \mathrm{Al}_{y}$ [28] and $\mathrm{Ni}_{50-x} \mathrm{Co}_{x} \mathrm{Mn}_{50-y} \mathrm{Al}_{y}$ [23,29] are also shown in the figure.

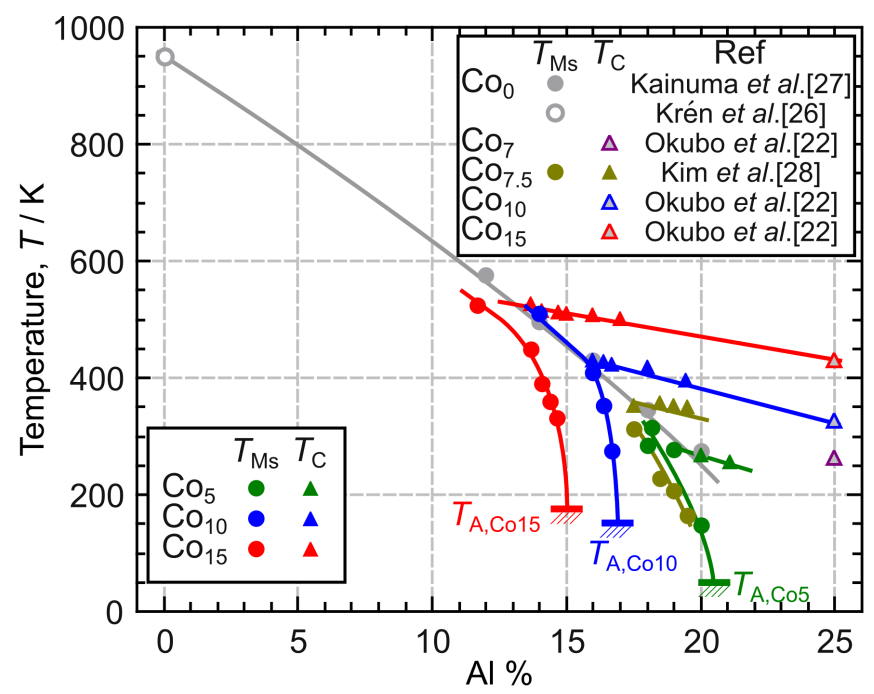

\section{Conclusions}

In this study, the magnetic properties of the $\mathrm{Ni}_{50-x} \mathrm{Co}_{x} \mathrm{Mn}_{50-y} \mathrm{Al}_{y}$ alloy system were systematically investigated with the purpose of raising the thermal transformation arrest temperature $\left(T_{\mathrm{A}}\right)$. The $T_{\mathrm{A}}$ was raised from $40 \mathrm{~K}$, for the first time in this system, to about $190 \mathrm{~K}$, by the substitution of Co for Ni. Furthermore, the critical magnetic field-temperature phase diagram for $\mathrm{Ni}_{40} \mathrm{Co}_{10} \mathrm{Mn}_{33} \mathrm{Al}_{17}\left(\mathrm{Co}_{10} \mathrm{Al}_{17}\right)$ was determined under a pulsed high magnetic field. Magnetic field hysteresis $H_{\text {hys }}$ during the magnetic field-induced reverse martensitic transformation was found to be greatly enlarged below the $T_{\mathrm{A}}$ for $\mathrm{Co}_{10} \mathrm{Al}_{17}$. The magnetic phase diagram for $\mathrm{Ni}_{50-x} \mathrm{Co}_{x} \mathrm{Mn}_{50-y} \mathrm{Al}_{y}$ was also determined in this study. Finally, a change in terminology is proposed, i.e., from "kinetic arrest phenomenon" to "thermal transformation arrest phenomenon", which is in line with the experimental results based on phenomenological understandings.

\section{Acknowledgments}

This work was supported by a Grant-in-Aid for Scientific Research and by a grant from the Japan Society for the Promotion of Science (JSPS). This work was also partially supported by MEXT, Japan, 
through a Grant-in-Aid for Scientific Research (23340096). A part of this work was carried out at the Center for Low Temperature Science, Institute for Materials Research, Tohoku University.

\section{Conflicts of Interest}

The authors declare no conflict of interest.

\section{References}

1. Sharma, V.K.; Chattopadhyay, M.K.; Roy, S.B. Kinetic arrest of the first order austenite to martensite phase transition in $\mathrm{Ni}_{50} \mathrm{Mn}_{34} \mathrm{In}_{16}$ : Dc magnetization studies. Phys. Rev. B 2007, 76, 140401.

2. Ito, W.; Ito, K.; Umetsu, R.Y.; Kainuma, R.; Koyama, K.; Watanabe, K.; Fujita, A.; Oikawa, K.; Ishida, K.; Kanomata, T. Kinetic arrest of martensitic transformation in the NiCoMnIn metamagnetic shape memory alloy. Appl. Phys. Lett. 2008, 92, 021908.

3. Xu, X.; Ito, W.; Umetsu, R.Y.; Koyama, K.; Kainuma, R.; Ishida, K. Kinetic arrest of martensitic transformation in $\mathrm{Ni}_{33.0} \mathrm{Co}_{13.4} \mathrm{Mn}_{39.7} \mathrm{Ga}_{13.9}$ metamagnetic shape memory alloys. Mater. Trans. 2010, 51, 469-471.

4. Xu, X.; Ito, W.; Tokunaga, M.; Umetsu, R.Y.; Kainuma, R.; Ishida, K. Kinetic arrest of martensitic transformation in NiCoMnAl metamagnetic shape memory alloys. Mater. Trans. 2010, 51, 1357-1360.

5. Umetsu, R.Y.; Ito, K.; Ito, W.; Koyama, K.; Kanomata, T.; Ishida, K.; Kainuma, R. Kinetic arrest behavior in martensitic transformation of NiCoMnSn metamagnetic shape memory alloy. J. Alloys Compd. 2011, 509, 1389-1393.

6. Kainuma, R.; Imano, Y.; Ito, W.; Sutou, Y.; Morito, H.; Okamoto, S.; Kitakami, O.; Oikawa, K.; Fujita, A.; Kanomata, T.; et al. Magnetic-field-induced shape recovery by reverse phase transformation. Nature 2006, 439, 957-960.

7. Ito, W.; Umetsu, R.Y.; Kainuma, R.; Kakeshita, T.; Ishida, K. Heat-induced and isothermal martensitic transformations from kinetically arrested parent phase in NiCoMnIn metamagnetic shape memory alloy. Scr. Mater. 2010, 63, 73-76.

8. Lee, Y.; Todai, M.; Okuyama, T.; Fukuda, T.; Kakeshita, T.; Kainuma, R. Isothermal nature of martensitic transformation in an $\mathrm{Ni}_{45} \mathrm{Co}_{5} \mathrm{Mn}_{36.5} \mathrm{In}_{13.5}$ magnetic shape memory alloy. Scr. Mater. 2011, 64, 927-930.

9. Kustov, S.; Golovin, I.; Corró, M.; Cesari, E. Isothermal martensitic transformation in metamagnetic shape memory alloys. J. Appl. Phys. 2010, 107, 053525.

10. Nayak, A.K.; Suresh, K.G.; Nigam, A.K. Metastability of magneto-structural transition revealed by sweep rate dependence of magnetization in $\mathrm{Ni}_{45} \mathrm{Co}_{5} \mathrm{Mn}_{38} \mathrm{Sb}_{12}$ Heusler alloy. J. Appl. Phys. 2011, 109, 07A906.

11. Xu, X.; Ito, W.; Katakura, I.; Tokunaga, M.; Kainuma, R. In situ optical microscopic observation of NiCoMnIn metamagnetic shape memory alloy under pulsed high magnetic field. Scr. Mater. 2011, 65, 946-949. 
12. Xu, X.; Katakura, I.; Kihara, T.; Tokunaga, M.; Ito, W.; Umetsu, R.Y.; Kainuma, R. Optical microscopic study on NiCoMnAl metamagnetic shape memory alloy by in situ observation under a pulsed high magnetic field. Mater. Trans. 2013, 3, 357-362.

13. Tong, H.C.; Wayman, C.M. Characteristic temperatures and other properties of thermoelastic martensites. Acta Metall. 1974, 22, 887-896.

14. Cesari, E.; Kustov, S.; Salas, D. Entropy changes in ferromagnetic shape memory alloys. Mater. Sci. Forum 2011, 684, 49-60.

15. Umetsu, R.Y.; Kusakari, Y.; Kanomata, T.; Suga, K.; Sawai, Y.; Kindo, K.; Oikawa, K.; Kainuma, R.; Ishida, K. Metamagnetic behaviour under high magnetic fields in $\mathrm{Ni}_{50} \mathrm{Mn}_{50-x} \mathrm{In}_{x}$ ( $\mathrm{x}=14.0$ and 15.6) shape memory alloys. J. Phys. D 2009, 42, 075003.

16. Umetsu, R.Y.; Ito, W.; Ito, K.; Koyama, K.; Fujita, A.; Oikawa, K.; Kanomata, T.; Kainuma, R.; Ishida, K. Anomaly in entropy change between parent and martensite phases in the $\mathrm{Ni}_{50} \mathrm{Mn}_{34} \mathrm{In}_{16}$ Heusler alloy. Scr. Mater. 2009, 60, 25-28.

17. Ito, W. Martensitic Transformation and Magnetic Properties in Ni-Mn Based Metamagnetic Shape Memory Alloys. Ph.D. Thesis, Tohoku University, 2009.

18. Ito, W.; Imano, Y.; Kainuma, R.; Sutou, Y.; Oikawa, K.; Ishida, K. Martensitic and magnetic transformation behaviors in Heusler-type NiMnln and NiCoMnln metamagnetic shape memory alloys. Metall. Mater. Trans. A 2007, 38A, 759-766.

19. Kainuma, R.; Ito, W.; Umetsu, R.Y.; Oikawa, K.; Ishida, K. Magnetic field-induced reverse transformation in B2-type NiCoMnAl shape memory alloys. Appl. Phys. Lett. 2008, 93, 091906.

20. Kindo, K. 100 T magnet developed in Osaka. Phys. B Cond. Mat. 2001, 294, 585-590.

21. Khovaylo, V.V.; Lyange, M.; Skokov, K.; Gutfleisch, O.; Chatterjee, R.; Xu, X.; Kainuma, R. Adiabatic temperature change in metamagnetic Ni(Co)-Mn-Al Heusler alloys. Mater. Sci. Forum 2013, 738-739, 446-450.

22. Umetsu, R.Y.; Endo, K.; Kondo, A.; Kindo, K.; Ito, W.; Xu, X.; Kanomata, T.; Kainuma, R. Magnetoresistance and transformation hysteresis in the $\mathrm{Ni}_{50} \mathrm{Mn}_{34.6} \mathrm{In}_{15.6}$ metamagnetic shape memory alloys. Mater. Trans. 2013, 3, 291-296.

23. Okubo, A.; Xu, X.; Umetsu, R.Y.; Kanomata, T.; Ishida, K.; Kainuma, R. Magnetic properties of $\mathrm{Co}_{50-x} \mathrm{Ni}_{x} \mathrm{Mn}_{25} \mathrm{Al}_{25}$ alloys with B2 structure. J. Appl. Phys. 2011, 109, $07 \mathrm{~B} 114$.

24. Wu, Z.G.; Liu, Z.H.; Yang, H.; Liu, Y.N.; Wu, G.H. Effect of Co addition on martensitic phase transformation and magnetic properties of $\mathrm{Mn}_{50} \mathrm{Ni}_{40-x} \mathrm{In}_{10} \mathrm{Co}_{x}$ polycrystalline alloys. Intermetallics 2011, 19, 1839-1848.

25. Yu, S.Y.; Cao, Z.X.; Ma, L.; Liu, G.D.; Chen, J.L.; Wu, G.H.; Zhang, B.; Zhang, X.X. Realization of magnetic field-induced reversible martensitic transformation in NiCoMnGa alloys. Appl. Phys. Lett. 2007, 91, 102507.

26. Fabbrici, S.; Albertini, F.; Paoluzi, A.; Bolzoni, F.; Cabassi, R.; Solzi, M.; Righi, L.; Calestani, G. Reverse magnetostructural transformation in Co-doped NiMnGa multifunctional alloys. Appl. Phys. Lett. 2009, 95, 022508.

27. Krén, E.; Nagy, E.; Nagy, I.; Pál, L.; Szabó, P. Structures and phase transformations in Mn-Ni system near equiatomic concentration. J. Phys. Chem. Solids 1968, 29, 101-108. 
28. Kainuma, R.; Gejima, F.; Sutou, Y.; Ohnuma, I.; Ishida, K. Ordering, martensitic and ferromagnetic transformations in Ni-Al-Mn Heusler shape memory alloys. Mater. Trans. 2000, 41, 943-949.

29. Kim, Y.; Han, W.B.; Kim, H.S.; An, H.H.; Yoon, C.S. Phase transitions and magnetocaloric effect of $\mathrm{Ni}_{1.7} \mathrm{Co}_{0.3} \mathrm{Mn}_{1+x} \mathrm{Al}_{1-x}$ Heusler alloys. J. Alloys Compd. 2013, 557, 265-269.

30. Ziebeck, K.R.A.; Webster, P.J. Helical magnetic order in $\mathrm{Ni}_{2} \mathrm{MnAl}$. J. Phys. F Met. Phys. 1975, $5,1756-1766$.

(C) 2013 by the authors; licensee MDPI, Basel, Switzerland. This article is an open access article distributed under the terms and conditions of the Creative Commons Attribution license (http://creativecommons.org/licenses/by/3.0/). 